\title{
Comparative Study on the in vitro Antibacterial Efficacy of Aqueous and Methanolic Extracts of Quercus infectoria Gall`s Against Cellulosimicrobium cellulans
}

\begin{abstract}
The in vitro antibacterial efficacy of aqueous and methanolic extract of Quercus infectoria Olivier (Fagaceae) galls was tested against Cellulosimicrobium cellulans using extract concentration ranging from 0.25 to $4 \mathrm{mg} \mathrm{mL}-1$. Both types of extract showed significant inhibition of C. cellulans growth with strong correlation between extract concentrations and degrees of antibacterial activity for concentrations ranging from 0.5 to $4 \mathrm{mg} \mathrm{mL}-1$. Although, slight reduction of average diameter of inhibition zones after $24 \mathrm{~h}$ of incubation for aqueous extract $(0.96 \pm 0.148 \mathrm{~cm})$ compared to methanolic extract $(1.00 \pm 0.182 \mathrm{~cm})$, both extracts still attained the MIC value beginning at a concentration of $0.5 \mathrm{mg} \mathrm{mL}-1$ but established higher concentration for the MBC at $2 \mathrm{mg} \mathrm{mL}-1$. The antibacterial activity of methanolic extract was also significantly affected by the temperature with an optimum inhibition zone being obtained at $30{ }^{\circ} \mathrm{C}(1.38 \pm 0.05 \mathrm{~cm})$ and this was reduced to approximately $20 \%$ at temperatures of above $50{ }^{\circ} \mathrm{C}$.
\end{abstract}

Keyword: Antibacterial, aqueous extract, Cellulosimicrobium cellulans, methanolic extraxt, Quercus infectoria 